\title{
A análise da rede de vínculos de autores de delitos como uma contribuição para a compreensão do comportamento delituoso
} um estudo de caso

\author{
Odilza Lines de Almeida
}

\section{SciELO Books / SciELO Livros / SciELO Libros}

ALMEIDA, O.L. A análise da rede de vínculos de autores de delitos como uma contribuição para a compreensão do comportamento delituoso: um estudo de caso. In: COELHO, M.T.Á.D., and CARVALHO FILHO, M.J., orgs. Prisões numa abordagem interdisciplinar [online]. Salvador: EDUFBA, 2012, pp. 75-95. ISBN 978-85-232-1735-8. Available from: doi: 10.7476/9788523217358.006. Also available in ePUB from: http://books.scielo.org/id/7mkg8/epub/coelho-9788523217358.epub.

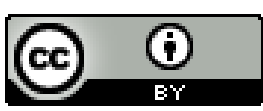

All the contents of this work, except where otherwise noted, is licensed under a Creative Commons Attribution $\underline{4.0 \text { International license. }}$

Todo o conteúdo deste trabalho, exceto quando houver ressalva, é publicado sob a licença $\underline{\text { Creative Commons }}$ Atribição 4.0. 


\section{A análise da rede de vínculos de autores de delitos como uma contribuição para a compreensão do comportamento delituoso: um estudo de caso ${ }^{1}$}

Odilza Lines de Almeida

\section{Introdução}

Este capítulo tem por objetivo apresentar a análise da rede de vínculos como uma contribuição para os estudos criminológicos, especialmente no que se refere ao desenvolvimento do comportamento delituoso. Para tal mister, conduzimos uma pesquisa de metodologia mista com o objetivo de identificar, numa unidade prisional, pessoas que assumiram ter uma trajetória delituosa e que se auto-intitulavam como sendo "do crime" e o impacto dos vínculos construídos durante

1 Este trabalho é proveniente da dissertação Histórias de (des)vínculos: um estudo com autores de delitos em regime de privação de liberdade, defendida no Programa de Pós-Graduação em Psicologia da UFBA e orientada pela Profa. Dra. Sonia Maria Rocha Sampaio, a quem renovo meus sinceros agradecimentos. 
o ciclo de vida no estabelecimento e na consolidação de uma carreira delituosa.

Esclarecemos que 'autores de delitos' são aqui vistos de modo similar aos desviantes de Becker (1996), isto é, como aqueles para quem o rótulo foi aplicado com sucesso posto que internalizado. Não é, portanto, uma qualidade da pessoa ou do ato que a pessoa comete, per si, mas uma conseqüência da aplicação por outros, de regras e sanções àqueles que transgridem as normas do grupo social. Já o conceito de 'carreira', também utilizado por esse autor, faz referência à sequência de movimentos dentro de um sistema e às contingências das quais depende essa mobilidade.

Consideramos, pois, que a rede de vínculos é uma dessas contingências e para sua análise desenvolvemos um modelo teórico (Figura 1), numa abordagem sistêmica, que privilegia os vínculos estabelecidos nos diversos contextos de desenvolvimento. Esse modelo foi construído a partir de uma perspectiva multirreferencial que articula pressupostos das seguintes abordagens: a Teoria do Controle Social (HIRSCHI, 2003), do campo da criminologia; a Teoria da Socialização Primária (OETTING; DONNERMEYER, 1988), proveniente da Psicologia Social e as Teorias do Apego (BOWLBY, 1984) e Ecológica (BRONFENBRENNER, 1979, 1986, 1996), oriundas da Psicologia do Desenvolvimento. Assim, partimos da concepção de que a rede de vínculos - conjunto envolvendo a pessoa e as relações que estabelece com seu meio - facilita ou não o envolvimento com o crime, considerando que as ligações estabelecidas entre os atores propiciam controles internos e externos. Foram tanto analisadas a configuração da rede (amplitude medida pelos contextos presentes), seu tamanho, estrutura e homofilia (relações com pessoas que cometem delitos) bem como reconstruídas as redes referentes aos períodos cruciais do desenvolvimento (infância, adolescência) e construídas as redes representativas do momento da pesquisa, quando o informante se encontrava em reclusão, e das expectativas do autor de delito ao sair da prisão. 


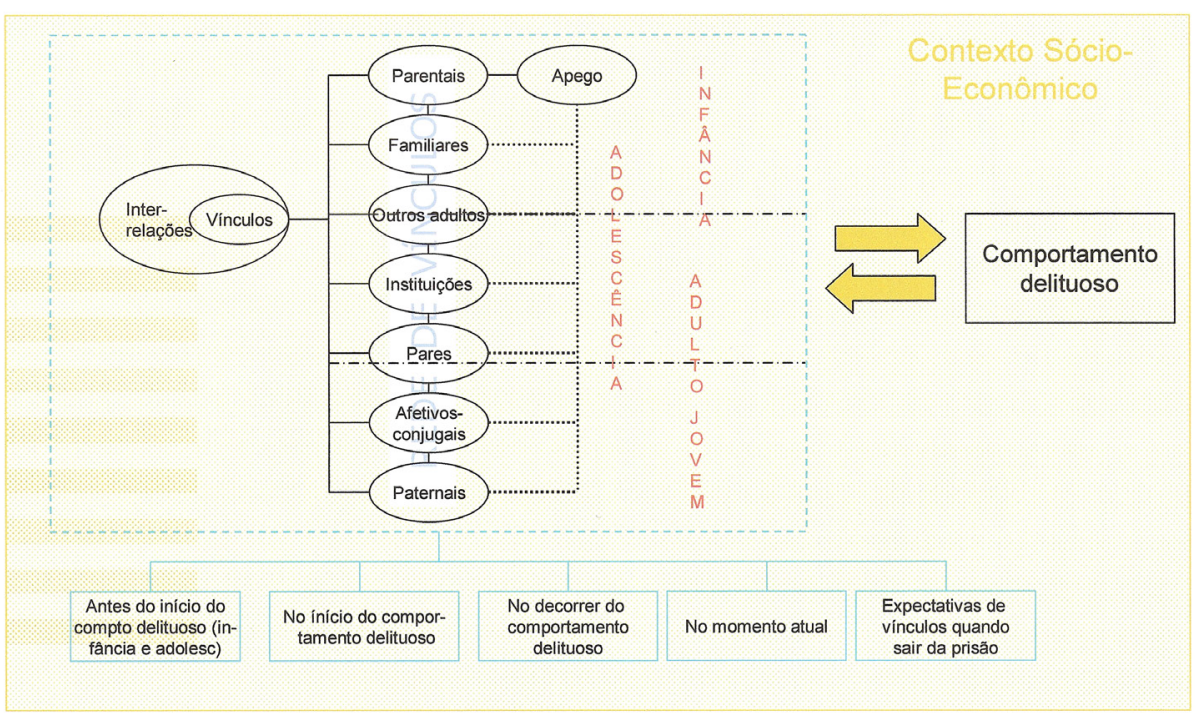

Figura 1- Modelo Teórico

Fonte: própria autora

Nesse modelo, compreendemos que o vínculo é um "espaço privilegiado de construção e de persistência de coisas compartilhadas" (CARVALHO, 2005), e é considerado como uma relação particular com um outro significativo, assumindo como pressupostos: a) a impossibilidade de ausência total de vinculação no contexto da vida humana; e b) que o vínculo comporta afeto positivo ou negativo, não implicando juízo de valor moral e constitui mecanismo de identidade e lugar no mundo. (CARVALHO, 2005) Carvalho (2005 apud BASTOS et al., 2006) propõe, ainda, para fins de sua análise que o vínculo seja considerado como "um padrão diferencial de interações entre parceiros em uma situação social, expressando seletividade em relação a certos parceiros ao longo de um período de tempo" (grifo do autor). Dessa forma, o vínculo comporta duas dimensões: seletividade e durabilidade. Assumimos a "durabilidade" enquanto repercussão e internalização - o que a Teoria do Apego chama de "modelo de representação" - daquelas relações estabelecidas e que perduram por um período considerável de tempo na trajetória de vida. Foram consideradas as relações e os vínculos estabelecidos com figuras parentais (pai, mãe ou substitutos); familiares (irmãos, tios, avós, primos etc.); outros adultos (professor, padres, pastores, pais de amigos, profissionais de instituições diversas etc.), pares (amigos e colegas de escola, trabalho); pessoas com quem 
mantêm vínculos amorosos íntimos (namorada, esposa, companheira etc.); com pessoas com as quais têm uma relação paternal (filhos, enteados, sobrinhos etc.) e com instituições (escolas, igrejas, casas de acolhimento, de programas sociais etc.).

De posse desse modelo, fomos a campo para identificar esses diversos vínculos na trajetória de adultos em regime de privação de liberdade. Apresentamos a seguir a análise da narrativa de um deles, Fernando, que cometeu um crime considerado grave, dentro do escopo do trabalho². Sua história foi reconstruída numa Linha de Vida na qual foram sistematizados os principais eventos narrados e os sentimentos e julgamentos relacionados a esses eventos, o que forneceu uma idéia da trajetória individual. A partir dessa sistematização as redes de vínculos foram identificadas e representadas graficamente através de genogramas, ${ }^{3}$ proporcionando uma compreensão de sua configuração nos diversos momentos do seu percurso até o momento da pesquisa.

\section{A história e a rede de vínculos de Fernando}

No momento da entrevista, Fernando contava com 22 anos e estava preso há 33 meses por homicídio qualificado, delito considerado grave. Os autos do processo relatam que Fernando desferiu uma série de socos na vítima - com a qual mantinha um relacionamento amoroso - que desmaiou depois de bater a cabeça numa pedra. Fernando, em sua narrativa, banaliza o delito: "Se tivesse justiça não era nem pra mim nem tá preso por causa do B.O. [boletim de ocorrência] que eu tive: a pessoa foi morta com um murro, com um murro só, e eu tô até hoje preso".

É o terceiro filho de uma prole de quatro, cada um de pai distinto. Mãe alcoólatra, ele e os irmãos são criados com a ajuda da avó materna e de um padrasto - que vai entrar em sua vida quando tinha por volta de oito anos e pelo qual demonstra grande gratidão e consideração:

2 "Delito" é aqui considerado como ação ou omissão, dolosa ou culposa, tipificada pelos Códigos legais vigentes. Os delitos foram classificados em: "leves" - com sanções previstas até 4 anos de reclusão, passíveis de serem transformados em penas alternativas, conforme o art. 44 do Código Penal (Decreto-Lei 2848, 1940); graves - aqueles tipificados pela Lei de Crimes Hediondos (Lei 8.072, 1990) e médios (os demais delitos que não se encaixam nos anteriores).

3 A rede de vínculos foi descrita de forma gráfica através de uma adaptação da técnica do genograma, utilizando-se o software GenoPro (v. Beta). 
"Pra mim, ele é mais do que um pai". Pelo pai biológico manifesta ressentimento por ele o ter deixado pequeno na barriga da mãe que, segundo ele, sofreu muito para criar os filhos. Vê o pai por uma única vez aos nove anos, mas "não dá muita ligança".

A infância de Fernando transcorre dentro do esperado para qualquer criança de seu estrato social: mora em um bairro popular, composto por pessoas de classe média baixa, mas com equipamentos disponíveis para a comunidade como escolas, igrejas, campo de futebol, além de sua localização ser próxima ao centro da cidade. As ruas desse bairro são calçadas, dispõem de água e luz. Vê o bairro como local de pessoas boas, não faz referência à violência ou a outras situações de risco. Teve dois amigos de infância com os quais brincava de bola, pipa, gude e que eram considerados como irmãos. Frequentou a escola até a segunda série. A análise da rede de vínculos, até aqui, fornece a seguinte configuração:

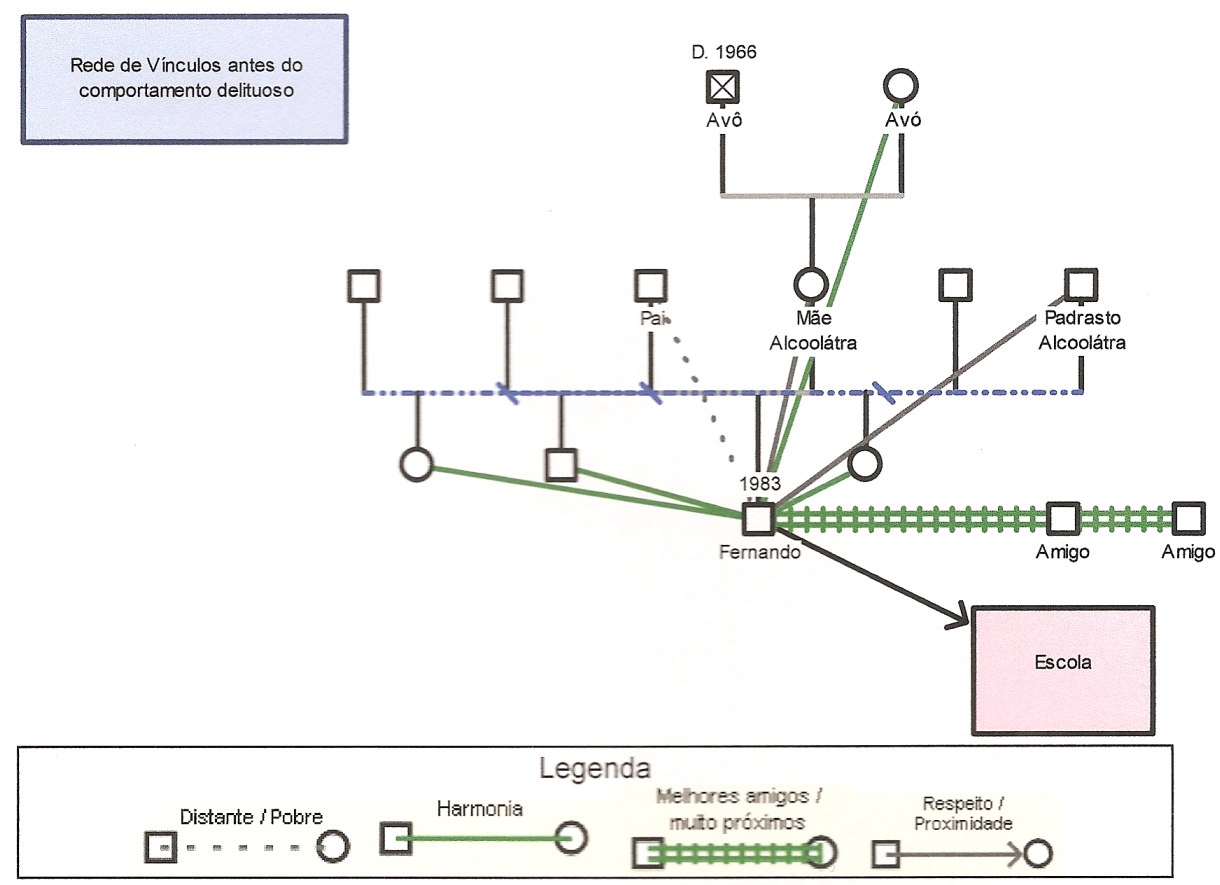

Figura 2 - Rede de vínculos antes do comportamento delituoso de Fernando Fonte: própria autora 
Fernando fornece um retrato de sua infância, momento que precede o início do comportamento delituoso, no seu caso. Nesse retrato, podemos identificar algumas particularidades como, por exemplo, a estruturação familiar. Parece haver um consenso, na área de conhecimento da Psicologia, de que a família tem uma função mediadora inquestionável no desenvolvimento do indivíduo nos primeiros anos de vida e seu impacto como agente socializador tem sido estudado tanto na psicologia do desenvolvimento quanto na psicologia social. Cabe, porém, lembrar que os modelos de família e, consequentemente, sua função e papéis acompanham o contexto histórico-social e econômico. Concordamos com Neder (2000, p. 28) quando considera que:

não existe, histórica e antropologicamente falando, um modelo-padrão de organização familiar; não existe a família regular. Menos ainda que o padrão europeu de família patriarcal, do qual deriva a família nuclear burguesa (que a moral vitoriana da sociedade inglesa no século XIX atualizou historicamente para os tempos modernos), seja a única possibilidade histórica de organização familiar a orientar a vida cotidiana no caminho do progresso e da modernidade. Pensar a família de forma plural pode significar uma construção democrática baseada na tolerância com as diferenças, com o Outro (grifos do autor).

A estrutura da família de Fernando foge ao padrão burguês de família. É um dos tantos modelos encontrados na sociedade contemporânea. Apesar das dificuldades e dos problemas encontrados neste contexto - "Essa época minha foi uma época muito precária mesmo que só a minha família, só minha mãe e minha vó trabalhava”-, essa família buscava dar o suporte e os referenciais necessários para o desenvolvimento de Fernando: "Ah, era bom. Todo mundo respeitava o outro. Até hoje, o relacionamento meu e dos meus irmãos é tudo... um ajudando o outro... Se um tá passando aperto, o outro ajuda outro. [...] É uma família unida." Nesta configuração, a avó tem um papel importante de suporte financeiro, moral e emocional. Fernando relata que a avó criou todos e sempre foi a figura a quem todos sempre respeitaram.

Aqui lembramos Kehl (2003) que faz uma reflexão sobre essas novas configurações, lembrando que o modelo familiar vigente como "regular" ou "normal", na verdade, vigorou por pouco tempo na história ocidental - do início do século XIX a meados do século XX. As condições econômicas, os métodos anticoncepcionais e a mudança do 
papel da mulher na sociedade também contribuem para as modificações da estrutura familiar e das funções que a mulher passa a assumir nessas novas estruturas. Há, contudo, ainda lembra Kehl (2003), todo um discurso de endeusamento da família oitocentista, patriarcal, bem como a responsabilização de sua "dissolução" pelos problemas de degradação social em que vivemos. Esse discurso pode ser percebido na mídia, alimentado por profissionais diversos os quais teimam em reproduzir teorias que não contemplam a pluralidade da família e dos demais contextos de desenvolvimento, além de criar necessidades em torno dessa família "ideal".

E à família já não se pode mais exigir que venha a suprir sozinha todas as necessidades da pessoa em formação e, ainda, que venha a arcar com toda a sua formação moral, identitária e social. Diz Reis (1985, p. 112):

Enquanto a criança aristocrata, a camponesa ou mesmo a operária se defrontavam com uma ampla gama de possibilidades de identificação, a criança burguesa tinha apenas as figuras parentais, ou acabava tendo na realidade apenas um objeto de identificação - o progenitor do mesmo sexo - em virtude da rigorosa divisão de papéis sexuais que presidia sua vida familiar.

Mas o que nos diz Fernando sobre essa estrutura?

Eu mesmo, pra ser sincero pra senhora, eu nunca nem senti falta dele [do pai] não... Que nunca me ajudou em nada, nunca me deu nada, nunca se importou por mim. [...] Eu já tive um padrasto já... Meu padrasto pra mim.. até hoje ele é vivo. Pra mim ele tem mais valor do que meu pai que me botou no mundo, que me fez. [...] Ele não é meu pai biológico, mas pra mim ele é mais do que um pai. Pra mim ele é tudo... Que esse aí que ajudou minha mãe a criar meus irmãos, foi ele que, ele que fez tudo, até hoje... Até hoje ele ajuda minha família.

Além da família, Fernando frequentava o contexto da escola, da rua nas brincadeiras com os pares e das casas dos amigos próximos. $\mathrm{O}$ modelo bioecológico de Bronfenbrenner (1979, 1986, 1996) considera-os como microssistemas e ressalta que a relevância das experiências nesses ambientes não se refere aos dados objetivos, mas ao modo como o ser em desenvolvimento percebe e experiencia esse contexto. Especifica, ainda, propriedades do ambiente que estimulam o processo de desenvolvimento. Dentre elas, podem ser citadas as interconexões entre os ambientes, 
as quais favorecem atividades compartilhadas e a comunicação de via dupla, e a quantidade de ambientes desenvolvimentais. Fernando não relata problemas como o alcoolismo da mãe e do padrasto, dados que foram fornecidos pela irmã mais velha através de um contato informal. Percebe-se, porém, que as interconexões entre os ambientes eram pobres: a família, por exemplo, não acompanhava o desempenho escolar; não se percebe, na sua narrativa, o movimento da família em torno desse aspecto da vida de Fernando. É um mesossistema fragilmente vinculado. Além disso, a quantidade de ambientes parece restrita.

No decorrer de sua trajetória, algumas características da rede de vínculos vão se modificando. Não parece haver causas específicas, nem vínculos que antecedem outros para essas mudanças, mas sim um movimento sincrônico de fortalecimento de alguns vínculos e deterioração de outros. Como numa mandala tridimensional, o movimento em uma parte modifica outras partes vinculadas e reestrutura o todo. A rede de vínculos vai se reestruturando na medida em que ligações são fortalecidas, desfeitas ou fragilizadas, de forma sistêmica, global. Essa re-estruturação pode ser visualizada na configuração da rede de vínculos, verificada no início do comportamento delituoso, aos doze anos:

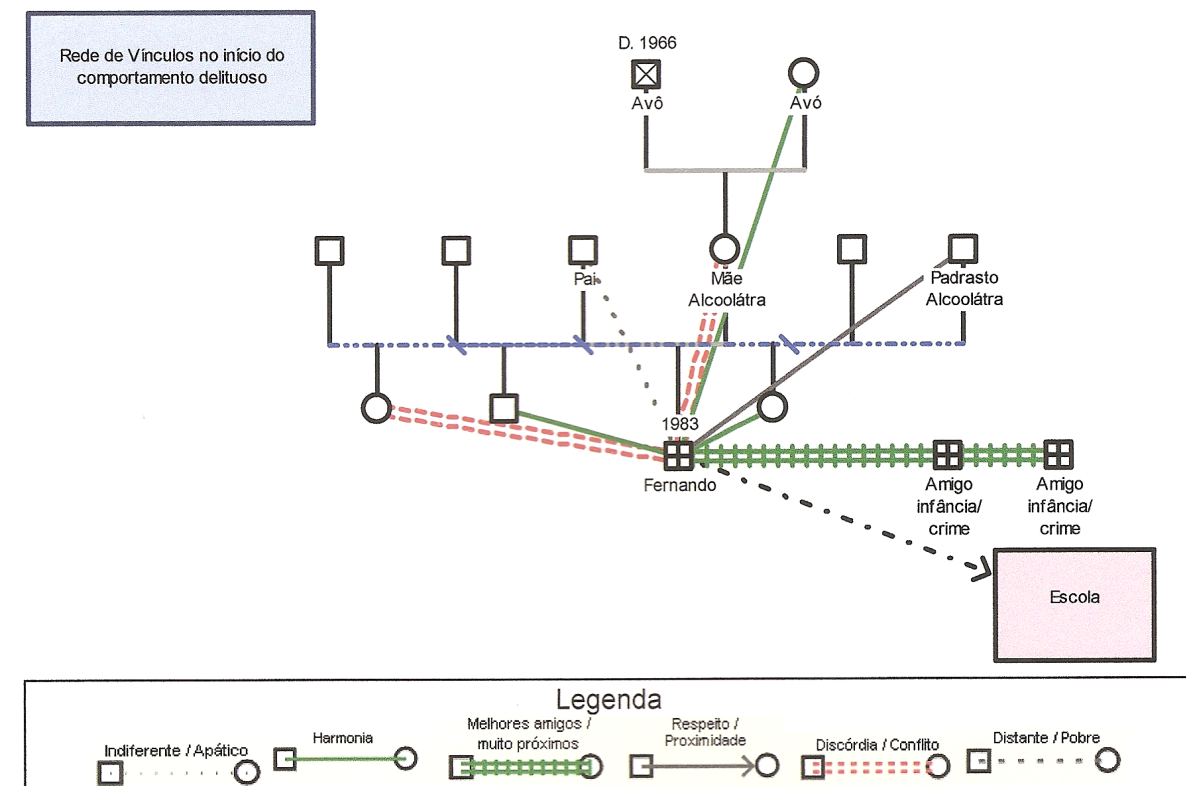

Figura 3 - Rede de Vínculos no início do comportamento delituoso de Fernando Fonte: própria autora 
Nota-se que alguns vínculos com membros da família nuclear estão enfraquecidos e constituem fontes de conflito (irmã mais velha e a mãe). Esse enfraquecimento está associado aos novos comportamentos apresentados - comportamento delituoso - e às mudanças de vínculos como o afastamento da escola, além da presença de companheiros (melhores amigos e muito próximos) que também apresentam comportamento delituoso.

A Teoria da Socialização Primária de Oetting e Donnermeyer (1998) defende que tanto o comportamento pró-social quanto o desviante seriam aprendidos no processo de socialização primária. Na sociedade ocidental, as fontes de socialização primária durante a adolescência seriam a família, a escola e o grupo de pares e cada uma dessas fontes envolve laços que fornecem canais para comunicação de normas. Ao aplicá-la à configuração encontrada no início do comportamento delituoso de Fernando e à narrativa coletada - "Minha vó, minhas irmã, meus irmão, tudo me aconselhava pra eu sair desse mundo"-, observa-se que apesar da presença das normas e dos vínculos pró-sociais no contexto da família nuclear, o comportamento delituoso se instalou. Outros agentes da socialização primária - escola e pares - parecem ter contribuído para esse acontecimento. O frágil laço com a escola principal agente socializador nessa teoria - juntamente com a aprendizagem ocorrida com os pares proporcionaram o ambiente propício à instalação do comportamento delituoso. Não se nota o apego, tanto no sentido de Bowlby quanto de Hirschi da Teoria do Controle Social, pois Fernando não se apresentava sensível à opinião dos familiares e, consequentemente, o comprometimento às regras estabelecidas estava enfraquecido. O envolvimento com tarefas convencionais foi sendo abandonado. As crenças eram compartilhadas, mas parecem terem sido internalizadas de forma débil e, assim, não foram eficazes para impedir a instalação do comportamento delituoso, provavelmente em função da força de outros vínculos.

Verifica-se também, neste momento, a restrição dos ambientes pelos quais Fernando circula. Não há uma expansão dos contextos de desenvolvimento. Fernando não se envolve profundamente com instituições ou com outros amigos. Sua rede pode ser caracterizada como pobre, o que dificulta a internalização de outros valores e do compartilhamento de outras crenças. O mundo era o que estava ali 
apresentado, e para tal mundo uma única possibilidade parecia-lhe existir.

Ao narrar como se deu o início do comportamento delituoso, diz Fernando:

Uma loucura da mente... Nois foi no centro, aí chegou ali na feira do Paraguai... Eu e outro... Aí um passou e levou uma calculadora, outro passou, levou um relógio... Aí nois vendeu, pegou o dinheiro, jogou vídeo-game, voltou de novo... Aí eu peguei um mini game e os outros, cada um pegou um relógio... Aí desse dia pra cá, começou... rouba isso, rouba aquilo... loucura de pivete...

Roubavam por prazer, pelo lúdico. O fruto do roubo também era revertido para esse fim ou ainda para adquirir roupas, bens de consumo. Wieviorka (1997), ao analisar a violência no nível individual, ${ }^{4}$ chama a atenção para um aspecto que foi colocado inicialmente nesse trabalho: a relação da violência com a busca da produção de sentido. $\mathrm{O}$ autor entende que o individualismo do mundo contemporâneo apresenta duas faces: o desejo de participar e de compartilhar do que a modernidade oferece e a necessidade de ser reconhecido como sujeito. O comportamento delituoso parece servir como um instrumento de acesso ao mundo prometido pelos meios de comunicação. A possibilidade de consumir e a ostentação dos bens adquiridos conferem ao autor de delitos um reconhecimento, uma visibilidade que lhe é constantemente negada no cotidiano. Fernando explica: "Pra mostrar pros outros aquele poder sem ter poder nenhum, mostrar que pode ter alguma coisa, mas sem ter nada, só ilusão mesmo da mente. Botou uma ilusão na mente e parece que vendou foi os olhos".

Garland (2002) esclarece que a chamada "nova criminologia da vida cotidiana” tem modificado a visão do crime e do autor de delitos. As versões do indivíduo inadaptado, carente afetiva e socialmente, deficiente e perigoso estão sendo substituídas pela figura do consumidor hedonista comum. "É simplesmente uma versão crua do indivíduo moderno, cuja 'identidade' depende de uma escolha de consumo e de imagens de si mais do que de formação moral, compromisso de valor ou autocontrole". (GARLAND, 2002, p. 78)

Apesar das dificuldades que a família enfrentava, Fernando não atribui à situação financeira familiar a sua entrada no mundo do cri-

4 Esse autor considera, ainda, os níveis internacionais, dos Estados e das sociedades. 
me: "Essa época foi uma época muito precária mesmo pois na minha família, só minha mãe e minha vó trabalhava. Aí nois passava muitas necessidades. Mas nem foi por causa disso não. Foi mais mente fraca mesmo". E o que seria "mente fraca", Fernando? "Mente fraca é a pessoa que não pensa o que vai fazer... Faz por impulso... Pensa uma coisa e já pensa que aquilo é o certo... Não pára pra pensar as coisa certa pra fazer. E cada vez que vai fazendo errado vai saindo errado."

Essa menção à "mente fraca" ou mesmo "cabeça fraca" e a dissociação entre situação econômica e comportamento desviante foram encontradas em outro trabalho que apresentava meninos de rua como foco. (SILVA, 1998)

A definição de "mente fraca" está também relacionada à influência de outras pessoas: "Os outro botava coisa na minha cabeça e eu achando que o crime era futuro". Esses outros eram os pares. Ao narrar como se deu o início do comportamento delituoso, relata Fernando:

Tinha um grupo nosso. Era uns dez, doze meninos, tudo de onze, doze, treze anos... Já tinha uns que era mais ligeiro, aí já botava na mente dos outro pros outro ir roubar pra ganhar dinheiro pra ir curtir, pra ter alguma coisa... Aí foi botando aquilo na cabeça e na hora que foi ver já tava envolvido no mundo do crime já... tão rápido... [...] toda noite, na esquina, ficava ali aquele grupinho, sempre todo dia naquele mesmo lugar e, no decorrer do dia a dia os que já roubava foi passando a idéia pros outros, aí daqui a pouco já estava todo mundo envolvido no crime...

Fernando e os seus amigos de infância encontraram juntos o caminho do crime. A influência dos amigos na adolescência no desenvolvimento do comportamento delituoso é verificada em Oetting e Donnermeyer (1998), quando discorrem sobre a vulnerabilidade da adolescência que é considerada como um período crítico, pois o potencial para aprender normas desviantes é relativamente alto. Fernando também teoriza sobre esse aspecto em particular:

Porque a pessoa de uma faixa assim de dez a, mais ou menos, uns quatorze anos, é muito fácil entrar na mente da pessoa dessa idade. Muito fácil mesmo. Porque a pessoa não tem raciocínio da mente e não tem conclusão do rumo que vai ser pra frente. Aí muitas vezes, o que a pessoa falar pra você é que é o certo. Mesmo que a mãe da pessoa chega e fala: 'ô meu filho, isso é errado', mas se o outro fala que é certo, a pessoa nessa idade, o raciocínio da mente dele é que o que o cara falou pra ele ali é o certo. Pode a mãe dele, o pai 
dele, todo mundo falar que é errado, mas pra ele é certo, que foi o que botaram na mente dele... Que foi o que aconteceu comigo...

Para Harris (1999, p. 225), "a meta da criança é ser uma criança bem sucedida” e não um adulto bem sucedido. É o mundo partilhado pelos grupos que constitui a referência de sucesso e competência, o que possibilita a transmissão da cultura. O grupo de pares serve para que a criança ou o adolescente possa se comparar ao outro e para se apropriar de um lugar, um status. A opinião e o julgamento por parte dos seus iguais têm um efeito devastador na construção da personalidade do indivíduo, defende Harris. Além disso, o grupo de pares constitui um espaço privilegiado de compreensão e de acolhimento diante das "incompreensões" familiares.

Mesmo envolvido no crime, Fernando trabalha com a mãe colhendo café. Também trabalha pegando carrego na feira. Relata que trabalhava muito e, nesse tempo, conheceu várias pessoas pelas quais nutre admiração como, barraqueiros e donos de loja na região em que trabalhava. Cita, inclusive, o dono de um bar pelo qual apresenta uma consideração que não tem pelos próprios parentes. Revela que essa pessoa testemunhou em seu processo na Justiça e se dispôs a ajudá-lo, coisas que os parentes não fizeram.

Fernando vivia em dois mundos: o mundo do trabalho e do relacionamento com pessoas "de bem" e o mundo do crime. Percebe-se a presença de outros adultos referenciais - o dono do bar - e de envolvimento com uma atividade produtiva. Os valores que eram difundidos em casa também estavam claros, mas numa análise mais minuciosa podem ser considerados ambíguos. Quando esclarece a utilização do dinheiro proveniente do roubo, Fernando revela:

Dinheiro de roubo não é aceito lá em casa não. Se for de roubo minha vó e minha mãe não aceitavam não. Podia, assim, dar alguma coisa pra minha mãe, pra minha avó. Aí eu comprava alguma coisa e dava; agora o dinheiro não aceitava não. Só algum dinheiro assim, quando eu ia trabalhar com alguma pessoa, ia pro café com minha mãe, aí eu chegava 'Aqui mãe, este dinheiro aqui é pra senhora'. Aí ela aceitava; agora dinheiro de roubo não aceitava não. Até hoje, não aceita não.

A adolescência de Fernando transcorre envolta no comportamento delituoso. Aos dezesseis anos, falece sua mãe. Esse momento é 
considerado um marco em sua vida: "Depois que minha mãe morreu, mudou totalmente. É diferente o modo de viver e de pensar. Eu antes eu só pensava em sair pra rua, em fazer zoeira, aprontar. Aí depois que minha mãe morreu, botei mais minha cabeça no lugar... mas só que não resultou em nada porque eu acabei vindo parar aqui nesse lugar...”.

Após a morte da mãe, a rede de vínculos de Fernando ficou assim configurada:

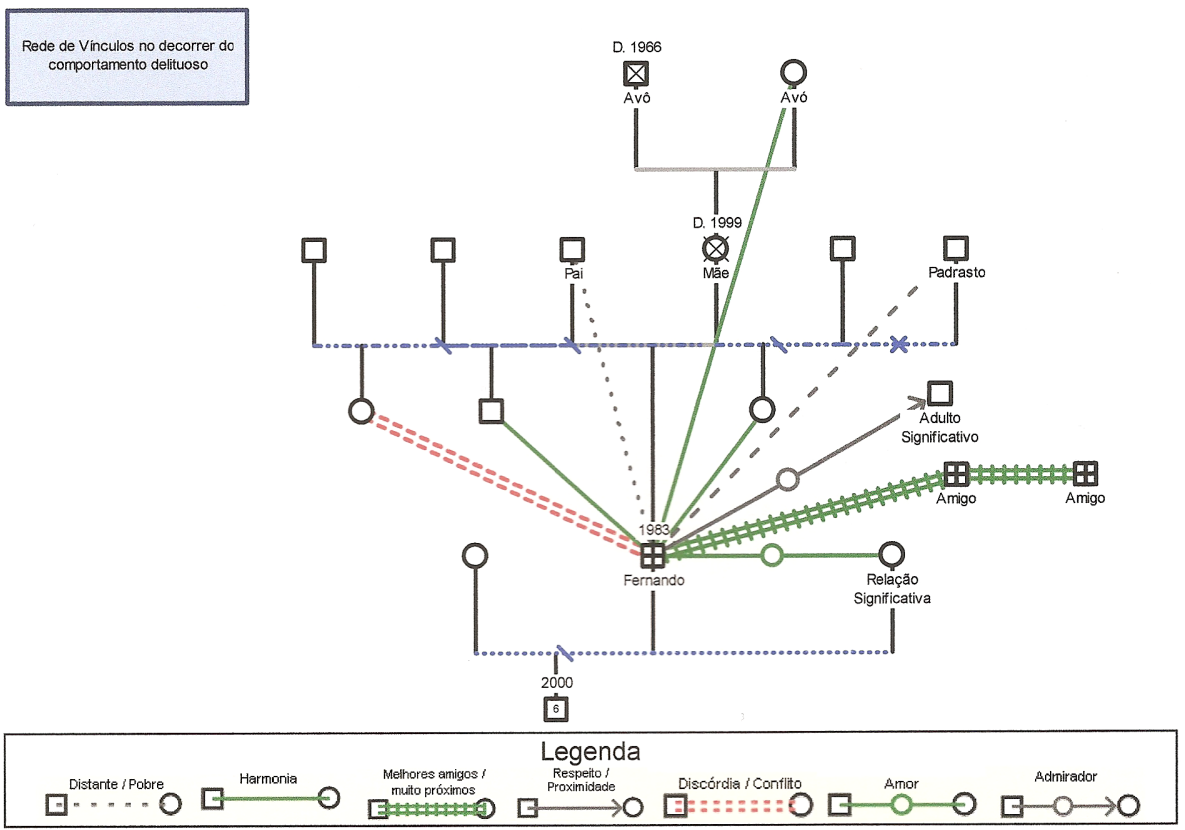

Figura 4 - Rede de vínculos de Fernando no decorrer do comportamento delituoso Fonte: própria autora

Mantém os vínculos familiares como antes se apresentavam. Nota-se o afastamento do padrasto que vai morar em outra casa após a morte da mãe, mas Fernando mantém o vínculo de admiração que nutria por ele. Nesse período, aparece ainda o adulto significativo - o dono do bar - e surgem os primeiros vínculos de cunho afetivo-sexual. Namora uma garota a qual engravida e tem o filho. Fernando mantém contato com a criança por seis meses. Tem uma atitude positiva em relação ao filho. "Eu senti como uma vitória muito grande e foi aí que eu vim acordar mais pra vida, d'eu sair desse mundo”. Depois, a família da 
mãe da criança leva os dois para outra cidade, pois a avó do menino não aceita o pai nem o dinheiro do crime. O que Fernando achou disso? "Eu achei uma atitude muito boa, o que ela fez; mas achei um pouco errado por ela ter criticado; se a pessoa roubar pra lá e comprar uma roupa pra uma criança não vai acontecer nada de mal porque quem está fazendo o mal não é a criança.” Já pediu à família para procurar o filho em outra cidade, porém, até hoje não obteve notícias. O vínculo com o filho é, portanto, frágil, não presencial. E, apesar do impacto inicial, a presença do filho em sua vida não se revelou propulsora de mudanças efetivas.

Em seguida, Fernando se envolve com uma garota com quem vai estabelecer uma relação afetivo-sexual significativa. Moram juntos por um ano. Considera-a uma pessoa muito importante em sua vida, até hoje. "Ela tem até raiva de eu ser desse caminho. Dava vários conselhos pra mim, eu não escutava. É uma pessoa concreta”. Nesse ínterim, Fernando cometeu o delito do qual está sendo acusado e saiu da cidade por um ano. Ao retornar, foi preso. A garota foi visitá-lo na delegacia e faz visitas esporádicas:

Namorado dela eu não considero mais não. Mas eu considero muito amigo dela. Porque a nossa amizade é forte mesmo. Não é mais um namoro, porque ela ficou dois anos em outro lugar... E agora já tem já uns quatro meses que ela veio aí. Mas eu, assim.. eu acho que entre eu e ela há uma amizade muito grande porque ela gosta muito de mim e eu gosto muito dela. É uma amizade muito concreta mesmo. Amizade pura mesmo. [...] Onde eu encontrava com ela era namoro e amizade ao mesmo tempo, pois muitas vezes ela desabafava comigo e eu desabafava com ela os problemas.

É um vínculo duradouro, de apego. Ainsworth (1991), ao discorrer sobre o apego no ciclo de vida, deixa claro que os componentes de apego e cuidado sustentam um relacionamento quando o componente sexual diminui sua força. O apego é duradouro e tende a persistir mesmo depois que o companheiro ou a companheira tenha partido, mesmo quando essa partida tenha sido desejada. Existe uma tendência de sentir falta do parceiro e de sentir-se sozinho. Esse apego, contudo, não foi suficiente para a descontinuidade do envolvimento com o crime.

Até aqui, então, a configuração dos vínculos de Fernando e os significados atribuídos a essas interações em contextos nos quais estão inseridas não possibilitaram a descontinuidade do envolvimento 
com o crime. Fernando vai seguindo, então, nesse caminho e acaba se envolvendo em um delito de homicídio que culmina com sua saída da cidade. Ao retornar, após um período foragido, Fernando é denunciado pelos amigos de infância. Essa denúncia vai se tornar um motivo de mágoa e de ressentimento com os antigos companheiros:

Fomos criado junto. Eu e mais dois. Eram os dois melhores amigos. Aonde nois ia tava junto; um almoçava na casa do outro, dormia na casa do outro. Já era mais de doze anos junto; aquela maior amizade. Aí chegaram e me traíram. Eu mesmo, eu me sinto muito revoltado com isso. Acho que eles não têm a mente e a capacidade de pensar no que é uma pessoa presa.

Na delegacia, onde inicialmente ficou custodiado, sofre três atentados porque ainda não tinha "conceito" ${ }_{5} \mathrm{e}$ atribui todo esse sofrimento à traição dos amigos. Essa passagem não funciona como instrumento de ressignificação dos próprios atos. A prisão rompe os vínculos com os amigos de infância e é a família que ressurge como suporte:

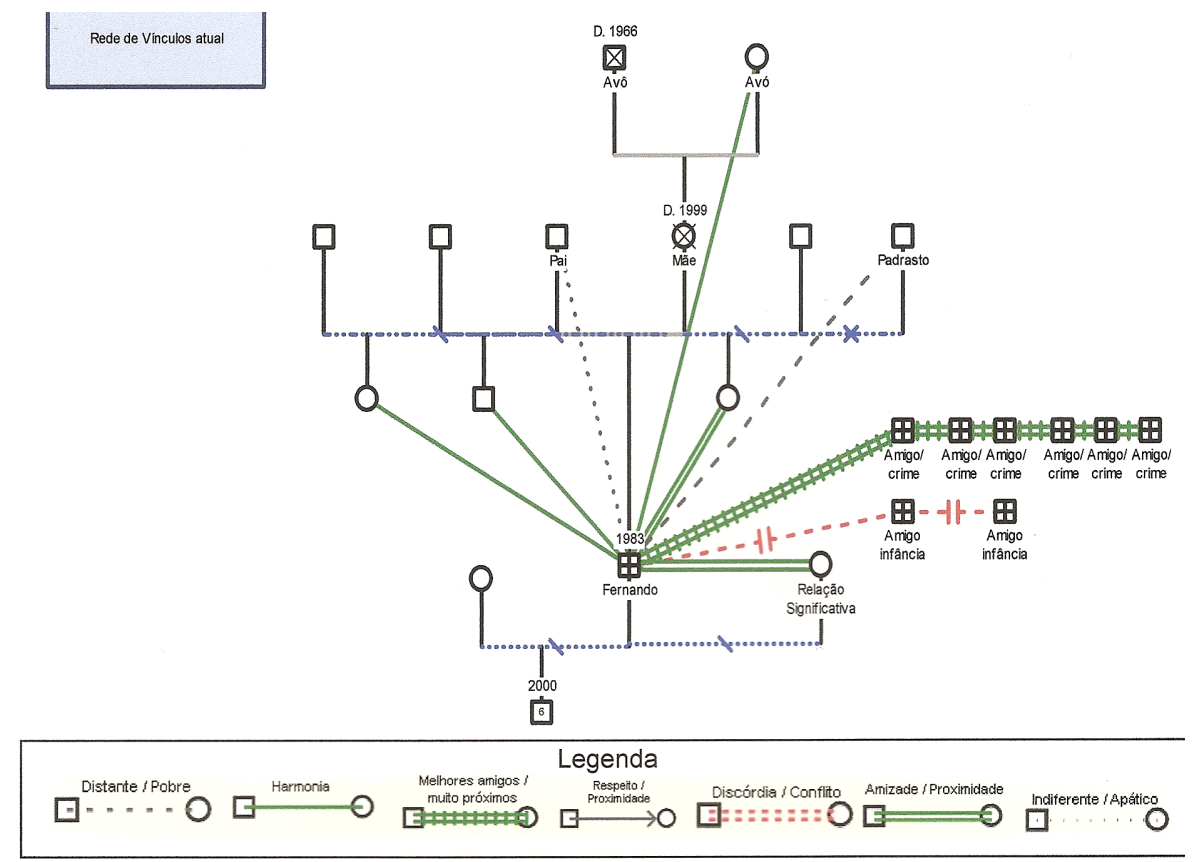

Figura 5 - Rede de vínculos durante o confinamento da prisão Fonte: própria autora

5 Termo que se refere à moral, reputação, consideração. 
A reaproximação da irmã mais velha e o estreitamento do vínculo com a irmã mais nova são observados nesta nova configuração. Os vínculos com os amigos de infância foram interrompidos. Em compensação, foram estabelecidos vínculos com outros pares delituosos que são os companheiros de prisão:

Eles são meus irmãos... Eu trato como meus irmãos, porque os cara não quer saber o que você é, o que você deixa de ser; o que você fez, o que você não fez; os caras só quer saber que você é amigo deles e se você tá correndo com eles.

A solidariedade encontrada no grupo faz com que Fernando valorize os vínculos estabelecidos na prisão, ao mesmo tempo em que reencontra a família e fortalece os vínculos com ela. Quais as consequências dessa nova configuração? Como Fernando supõe este tempo prospectivo? "Só vou poder contar com os meus irmãos, mesmo. Só. Acho que mais ninguém. Só os meus irmãos mesmo e minha vó. Porque não tem uma pessoa pra me ajudar, não tem ninguém. É só minha família mesmo”. Ficam assim, então, as expectativas de vínculos de 90 Fernando:

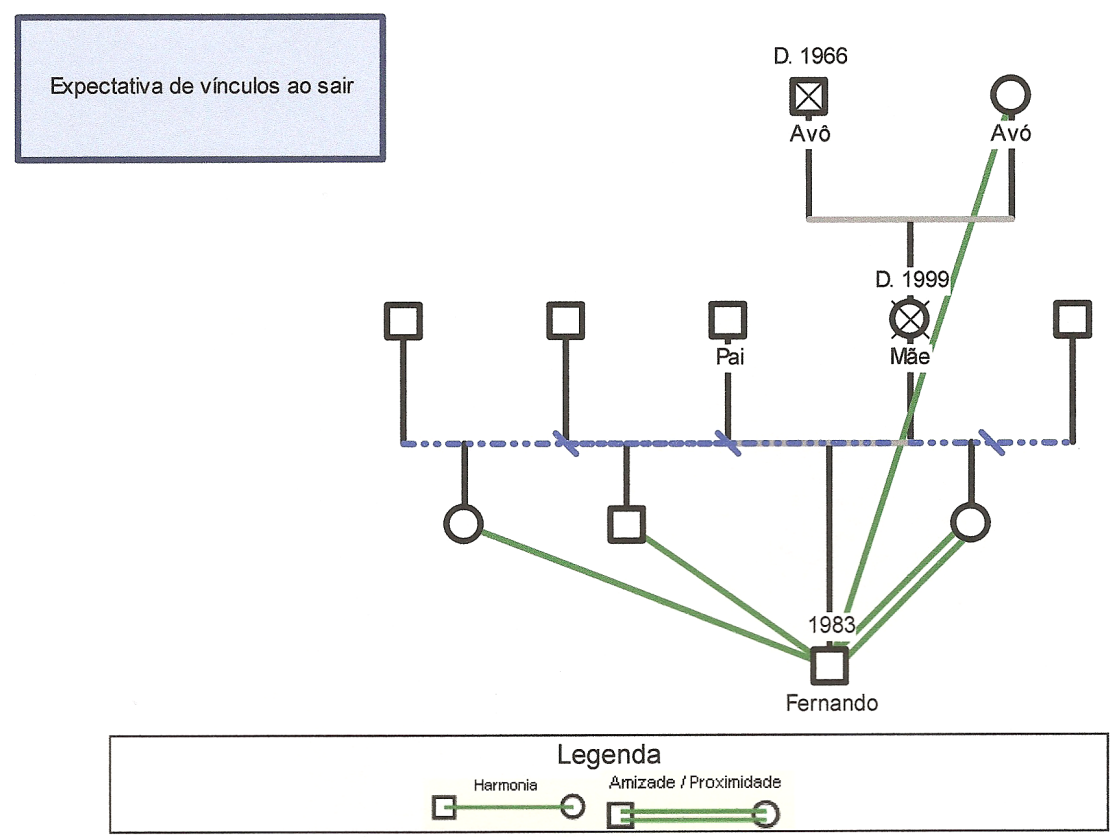

Figura 6 - Expectativa de vínculos de Fernando ao sair da prisão Fonte: própria autora 
A rede de vínculos apresentada por Fernando no decorrer da sua trajetória é caracterizada pela existência de vínculos fortes com seus pares, moderados com sua família e adultos significativos e frágeis com seu filho. No momento da construção dos dados, os vínculos com a família estavam em processo de fortalecimento. A maioria dos vínculos apresenta bi-direcionalidade, isto é, os atores envolvidos mantinham com Fernando a mesma qualidade de vínculo que ele. Os contextos de desenvolvimento são restritos: nota-se o microssistema da família nuclear, do grupo, da escola e da prisão. No entanto, não foram percebidas interconexões entre esses ambientes através de pessoas que transitassem por mais de um espaço, possibilitando a troca de informações e intervenção. É uma rede pequena e a homofilia é percebida na presença de outros autores de delitos. $\mathrm{O}$ contexto socioeconômico parece interferir na restrição dos ambientes, mas não justifica a ausência de outros familiares, de outras instituições e da interconexão entre os microssistemas. Essa restrição e a homofilia - que perdura na sua passagem pela prisão - podem contribuir para a continuidade no crime caso não ocorram mudanças nessa configuração, segundo o modelo utilizado nesse trabalho.

\section{Conclusão}

O autor de delito ora estudado, bem como os demais da investigação original, é protagonista do que usualmente chamamos de street crime na literatura internacional (ALLEN, 2005; DIMASCIO, 2004) ou "criminalidade de rua" na literatura nacional (NORONHA; MACHADO, 2002): ele é pobre, pratica em geral delitos como roubo, assalto e vandalismo, e pode ou não ser usuário de drogas ilícitas.

Retomando a questão do contexto, podemos dizer que cada sociedade, cada momento histórico fabrica seus próprios desviantes. Young (2002) classifica as sociedades como antropofágicas ou antropoêmicas a partir do modo como lidam com esses desviantes: engolindo-os, incluindo-os e tornando-os seus ou vomitando-os, conservando-os fora da sociedade, excluindo-os, comparando essas sociedades, assim, com os processos de canibalismo e bulimia. Considera, assim, que o mundo moderno tanto ingere quanto ejeta; é excludente e includente. $\mathrm{O}$ autor afirma que o mal-estar nas sociedades da modernidade recente não é 
produto da simples exclusão, mas um processo bulímico de inclusão e exclusão: inclui o indivíduo através dos meios de comunicação que dita os padrões de consumo e o exclui quando não proporciona a possibilidade de atingir esses padrões. Como diria Bauman (1998, p. 24), são "consumidores falhos", isto é, "pessoas incapazes de responder aos atrativos do mercado consumidor" e, ainda, impedidos de freqüentar os templos consumistas. Aqueles que não recuam diante da impossibilidade do consumo vão em busca da uniformidade com o outro que é visto como consumidor competente e, para tal mister, passam por cima das leis instituídas. "[...] eles não são mais do que entusiastas da pós-modernidade, aprendizes vorazes e devotos crentes da revelação pós-moderna, ávidos por levar as receitas de vida sugeridas por aquela lição até sua conclusão radical”. (BAUMAN, 1998, p. 26)

O autor de delitos cuja história foi aqui analisada toca exatamente nesse ponto quando menciona sobre o que o fez se manter no crime: "mostrar que tem poder" através do comportamento ou dos resultados conseguidos com o delito. O “poder”, em nossa sociedade pós-moderna, 92 é representado pelo consumo, pela velocidade com que o indivíduo adquire as novidades, pela forma com que descarta bens e pessoas. Mas, certamente, é vago e inútil responsabilizar a "sociedade" pelos atos desviantes, pois isso equivaleria a adotar uma visão passiva do sujeito. Minayo no Prefácio do livro de Assis (1999, p. 11) aponta a necessidade da visão dialética entre o indivíduo e seu meio para que possamos compreender que nenhuma escolha humana é explicada apenas por determinismos sociais apesar de que sejam realizadas a partir das condições dadas.

Notamos na fala do autor de delitos, por outro lado, uma autoculpabilização que revela pouca reflexão sobre esse enredamento existente entre indivíduo e sociedade. DiMascio (2004), ao perguntar a um interno na Prisão Grateford de segurança máxima na Pensilvânia, sobre o motivo pelo qual alguns deles passam anos na prisão e imploram para serem liberados e, depois, rapidamente se envolvem em problemas e voltam para prisão, obtém a resposta. "Eles não sabem como agir diferente. Fazem o que a cultura ensina. Não sabem o que é desafiar a cultura da rua”. Responderíamos da seguinte forma à pergunta de DiMascio: do nosso ponto de vista, a rede de vínculos que o indivíduo estabelece pode limitar ou ampliar suas possibilidades de experiências 
e de aprendizados e pode permitir escolhas e estabelecer controles. Ele pode fazer diferente se houver a possibilidade de fazê-lo. Como dito anteriormente, essa rede vai se reconfigurando na medida em que vínculos são celebrados, fortalecidos ou são desfeitos, enfraquecidos, sem haver, necessariamente, uma sequência causal.

Vê-se que nenhum dos vínculos, isoladamente, nos leva a uma compreensão do envolvimento do indivíduo no comportamento delituoso. O entrelaçamento entre os vínculos, a forma como estão organizados facilitam ou dificultam esse envolvimento conforme previsto no nosso modelo teórico. Por sua vez, a instalação do comportamento delituoso interfere na rede de relações e vínculos estabelecidos pelo indivíduo, reorganizando-a: restringe alguns tipos de vínculos e amplia outros. Essa rede também se caracteriza por ser dinâmica, pois os eventos no curso da vida vão modificando-a. A própria prisão, no caso de Fernando, foi um acontecimento crucial para a retomada de vínculos parentais e familiares.

Diante dos dados coletados, algumas indicações de atuação podem ser pensadas como, por exemplo, nas políticas de acompanhamento de egressos no sentido de implantação de programas que visem à ampliação das redes nas diversas dimensões da vida da pessoa - ação plenamente justificada pelas contribuições de Bronfenbrenner e corroboradas nesse trabalho - ou, ainda, no curso do período de reclusão possibilitar o resgate e fortalecimento de vínculos que contribuam para uma reinserção social que propicie a descontinuidade do comportamento delituoso.

\section{Referências}

AINSWORTH, M.D.S. Attachmente and other affectional bonds across the life cycle. In PARKES, C.M.; STEVENSON-HINDEN, J; MARRIS, P. Attachment across the life cycle. Routledge: London, 1991.

ALLEN, C. The Links Between Heroin, Crack Cocaine and Crime: where does street crime fit in? British journal criminology, v. 45, p. 355-372, 2005.

ASSIS, S. G. Traçando caminhos em uma sociedade violenta: a vida de jovens infratores e de seus irmãos não-infratores. Rio de Janeiro: FIOCRUZ, 1999. 
BASTOS, A.C.S., CARVALHO, A.M.A., RABINOVICH, E.P. \& SAMPAIO, S.M.R. Vínculos e redes sociais em contextos familiares e institucionais: uma reflexão conceitual. Psicologia em Estudo, v. 11, n. 33, p. 589-598, 2006.

BAUMAN, Z. O mal-estar da pós-modernidade. Rio de Janeiro: Jorge Zahar Editor, 1998.

BECKER, H. Outsiders: studies in the sociology of deviance. New York: The Free Press, 1966.

BOWLBY, J. Apego. São Paulo: Martins Fontes, 1984.

BRASIL. Decreto-lei n. 2.848, de 7 de dezembro de 1940. Código penal. Brasil, 1940.

BRASIL. Lei N. 8.072, de 25 de julho de 1990. Dispõe sobre os crimes hediondos, nos termos do art. $5^{\circ}$, inciso XLIII, da Constituição Federal e determina outras providências. Brasília, DF, 1990. Planalto.gov.br.

Disponível em: <http://www.planalto.gov.br/ccivil_03/leis/L8072compilada. htm> Acesso em: 23 jan. 2006.

BRONFENBRENNER, U. A ecologia do desenvolvimento humano: experimentos naturais e planejados. Porto Alegre, RS: Artes Médicas, 1996.

BRONFENBRENNER, U. Context of Child Rearing: problems and prospects. American psychologist, v. 34, n. 10, p. 844-850, 1979.

BRONFENBRENNER, U. Ecology of the family as a Context for Human Development: research perspectives. Developmental psychology, v. 22, n. 6, p. 723-742, 1986.

CARVALHO, A. M. A. Em busca da natureza do vínculo: uma reflexão psicoetológica sobre grupos familiares e redes sociais. In: PETRINI, J.C.; CAVALCANTI, V.R. (Org.). Família, sociedade e subjetividades: uma perspectiva multidisciplinar. Petrópolis, RJ: Editora Vozes, 2005, p. 183-194.

DIMASCIO, W. M. Reflections: Ending the culture of street crime. The prison journal, v. 84, n. 4, p. 428-478, 2004.

GARLAND, D. Discursos sediciosos: crime, direito e sociedade. Rio de Janeiro: Editora Revan, 2002.

HARRIS, J.R. Diga-me com quem anda... Rio de Janeiro: Objetiva, 1999.

HIRSCHI, T. Una Teoría del Controle de la Delincuencia. Capítulo criminológico, v. 31, n. 4, p. 5-31, 2003.

KEHL, M.R. Em defesa da família tentacular. In: GROENINGA, G.C.; 
PEREIRA, R.C. (Org.) Direito de família e psicanálise: rumo a uma nova epistemologia. Rio de Janeiro: Imago, 2003.

NEDER, G. Ajustando o Foco das Lentes. In: KALOUSTIAN, Sílvio Manoug (Org.). Família, a base de tudo. 4. ed. São Paulo: Cortez, Brasília, DF: UNICEF, 2000.

NORONHA, C.N. \& MACHADO, E.P. Pelos Filtros de Circe: violência, insegurança e controle social na mídia impressa. Espacio abierto, v. 11, n. 4, p. 639-663, 2002.

OETTING, E.R.; DONNERMEYER, J.F. Primary Socialization Theory: the etiology of Drug Use and Deviance. I. Substance use \& misuse, v. 33, p. 995-1026, 1998.

PAPALIA, D. E.; OLDS, S. W. Desenvolvimento humano. 7. ed.. Porto Alegre, RS: Artes Médicas Sul, 2000.

REIS, J.R.T. Família, Emoção e Ideologia. Apud Lane, S.T.M e Codo, W. Psicologia social: o homem em movimento. 2 ed. São Paulo: Brasiliense, p. $99-124,1985$.

ROSSETI-FERREIRA, M.C.; AMORIM, K. S., SILVA. Rede de Significações: alguns conceitos básicos. In: ROSSETI-FERREIRA, M.C.; AMORIM, K.S; SILVA, A.P.S.; CARVALHO, A.M.A.(Org). Rede de significações e o estudo do desenvolvimento humano Porto Alegre, RS: Artmed, 2004. p. 23-34.

SILVA, R.C.O. A porta entreaberta. Práticas e representações em torno das relações entre casa e rua junto a crianças de camadas populares em Florianópolis. 1998. Dissertação (Mestrado) - Centro de Filosofia e Ciências Humanas, Universidade Federal de Santa Catarina, 1998.

WIEVIORKA, M. O novo paradigma da violência. Tempo social - revista de sociologia da USP, v. 9, n. 1, p. 5 - 41, 1997.

YOUNG, P. Canibalismo e Bulimia. A Sociedade Excludente: exclusão social, criminalidade e diferença na modernidade recenteRio de Janeiro: Revan , 2002. p. 91 - 143. (Col. Pensamento Criminológico, v. 7) 